\title{
Territories in the Middle of the Ford. Mapping and Knowledge for Nature-Based Approach in the South Italy
}

\author{
Giuseppe Guida*D, Giovanni Bello and Valentina Vittiglio
}

Department of Architecture and Industrial Design, University of Campania "Luigi Vanvitelli", 81100 Caserta, Italy; giovanni.bello@unicampania.it (G.B.); valentina.vittiglio@unicampania.it (V.V.)

* Correspondence: giuseppe.guida2@unicampania.it

Citation: Guida, G.; Bello, G.; Vittiglio, V. Territories in the Middle of the Ford. Mapping and Knowledge for Nature-Based Approach in the South Italy. Sustainability 2021, 13, 6351. https://doi.org/10.3390/ su13116351

Academic Editors: Angela Colucci and Adriana Galderisi

Received: 18 May 2021

Accepted: 1 June 2021

Published: 3 June 2021

Publisher's Note: MDPI stays neutral with regard to jurisdictional claims in published maps and institutional affiliations.

Copyright: (c) 2021 by the authors. Licensee MDPI, Basel, Switzerland. This article is an open access article distributed under the terms and conditions of the Creative Commons Attribution (CC BY) license (https:/ / creativecommons.org/licenses/by/ $4.0 /)$.

\begin{abstract}
The paper investigates a particular phenomenon of the industrialization of Southern Italy, starting from the second post-war period, and, in particular, the unsolved relationship between some large industrial areas and the territories of the medium and small cities on which such productive "plates" have been installed. The town planning policies and instruments with which the industrialization of Southern Italy was planned, on the contrary, foresaw a strong integration between urban fabric and industrial agglomerations. Through the case study of the province of Caserta, the research illustrated by the paper investigates, first of all, the policies that supported this process of industrialization and what the territorial effects of this phenomenon were. Next, the paper illustrates the method of knowledge and mapping of the territory of the case study of the industrial development area of Caserta. The data will be collected in a GIS platform that will return the following condition that is nowadays not available: analytical maps of the brownfield areas and the identification of the areas still intact, agricultural or green areas, urban areas and infrastructures, which trace a cognitive framework addressed to the project in which it will possible to experiment some possible eco-innovative and nature-based solutions.
\end{abstract}

Keywords: industrial areas; regenerative landscape; eco-solutions; mapping; urban planning

\section{Introduction}

The territorial results of the planned industrialization of the territories and, consequently, of the geographies of the soils in the post-war period have been the subject of varied studies in the fields of politics, economics, history and urban knowledge. They have been carried out by relating the specificities of the theme with the economic and social changes of those years, and with the origin, especially in the urban field, of the planning models adopted (Limiting the field of interest to the specific one of this essay, some useful references can be [1-5]. In regards to economic and political analysis [6-10] can be used properly for urban-territorial studies. Finally, for a historical reading of the phenomenon [11-14] are useful). This is a multidisciplinary reflection that, viewed from the perspective of the planning of contemporary territories and critical economic and social issues, offers a framework in which it is possible to provide an unprecedented reading that is also precise and technically relevant, while being aimed at rethinking the generative elements of the urban project for these territorial areas.

The essay is part of the research path PURE (productive and urban metabolism resources eco-solutions for new lands). PURE is an interdisciplinary research project conducted by the Department of Architecture and Industrial Design at the University of Campania "Luigi Vanvitelli". The project has been funded within the V:ALERE 2020 program (referred to as the Rector's Decree. 475 of 9 July 2020), and the scientific coordinator is Prof. Giuseppe Guida (research team: Francesca Castanò, Rossella Franchino, Caterina Frettoloso, Nicola Pisacane, Valentina Vittiglio). It is aimed at reading the industrial phenomenon set in motion by specific policies from the 1960s for the South of Italy, with the 
changes, often unexpected and unpredictable, caused by this phenomenon on territorial arrangements, up to a description of current conditions and a possible methodological form for regenerative design practices. The focus of the research is on the great intervention of the industrial development area of the province of Caserta, in Campania (Figure 1). The research provided the opportunity, still innovative, to reread the territories, bringing out the kaleidoscope of conditions that are so far partly unknown. To emphasize the original intentions of the policies and plans developed in the post-war period and the present condition is useful, perhaps now necessary, to define a field of mediation between production, regional policies, environmental regeneration and spatial adequacy [15], while proposing eco-innovative strategies.

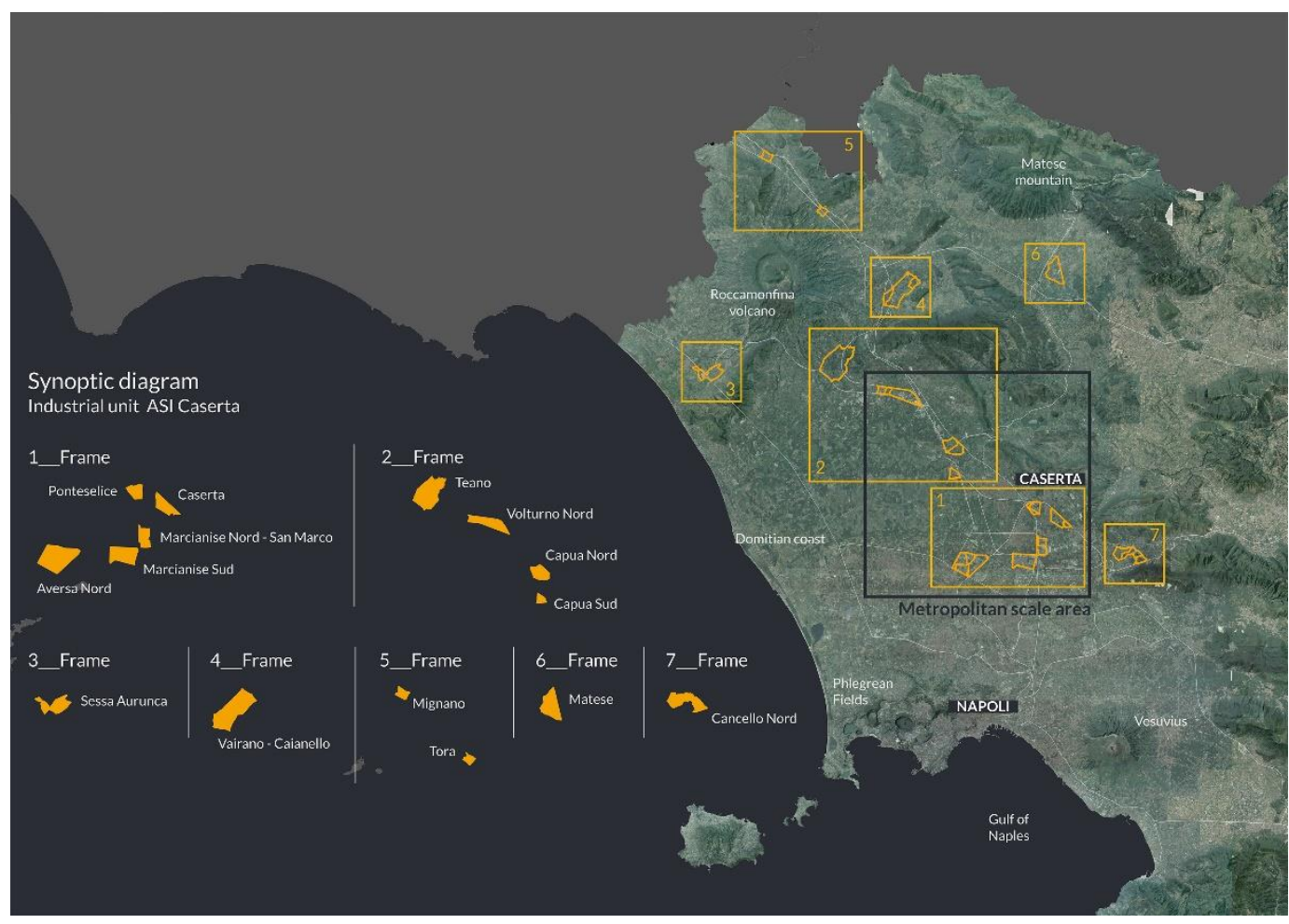

Figure 1. Regional framing of Caserta industrial development area. Source: PURE team.

The story of a territory has slowly generated both a new topology as well as a new geography, cognitive facts without which plans remain in their vagueness and ineffectiveness. Today those territorial plans initially analyzed by Paolo Radogna in 1965, in Issue 45 [7] of the important Italian magazine Urbanistica during their genesis (with a subsequent analysis by Marcello Vittorini in number 57 [8] of the same magazine, which highlighted a first "imbalance" generated by those industrial policies), are now "fossils of the contemporary", which foretold of a future never truly fulfilled and deposited on the great plain of Campania Felix as "real facts", "unfinished facts" (determined by the absence of adequate public direction) and, finally, imaginary facts (only traced on the maps of the town development plans and programs). These are converging elements in defining the territorial "palimpsest" [16] that emerges from the general crisis of these territories and this essay, with the partial view of urbanism, tries to reread so as to rethink the future.

The following text first traces the question of the planned industrialization of Southern Italy, comparing it with similar international experiences and focusing on the area of the province of Caserta. To follow, it has further deepened the context of intervention, circumscribing the field of interest only to the industrial agglomerations of Marcianise and North Volturno, and the importance that the concept of eco-innovative solutions (EIS) [17] and nature-based solutions $(\mathrm{NbS})[18,19]$ assumes within declining industrial environments. 
The hypotheses of the PURE research project, and the objectives to be achieved, are then clarified. The next section gives account both of the methodological framework in which the PURE research project was developed, and of the complex cartographic restitution of the territory. Compared to the latter, a georeferenced mapping has been defined that contains the main critical territorial issues in terms of land use, use destinations, infrastructure, explaining data, and "dimensions" of the territorial issues that have emerged.

\section{The Industrial Dimension and the Genesis of a New Urban}

The industrial development areas (in Italian Aree di Sviluppo Industriale-ASI) were established by law 634 of 1957 with the objective to heal the imbalance in the distribution of the national industry, through measures to support new industrial settlements for poles in the south. This operation was managed and financed by the Cassa per il Mezzogiorno, and was preceded by a pre-industrializationphase in which the action of the Cassa was dictated by the cogency of the agricultural question and unfolded through the first transformation and infrastructuring of the south. The ASI were implanted, following the indications of the circulars following law $634 / 57$, according to the special regulatory plans. These plans were given as the status of a territorial plan of coordination, therefore the municipal plans were subordinate to it, without any coordination of their forecasts. Currently, the governance of the ASI is entrusted to the appropriate consortia (which include the municipalities, provinces, chambers of commerce and other interested bodies) that regulate the operation and drafting of the ASI plans. From the morphological point of view, each ASI, whose localization was previewed in "particularly qualified" contexts, is composed of various areas called agglomerates. Within each agglomeration, in addition to services and production, logistic and trade infrastructures, areas for public services were also included, which were equipped and with green spaces, while also having standards to be integrated with the urban areas to which they were connected. In the territories with a lesser predisposition to the presence of industries, smaller sized settlements were allowed; they were called industrial nuclei of a widespread nature, and in many cases caused the decadence of the concentration and polarization logic contained in the founding law. The assumption was that, at the industrial sites, the existence and multiplication of agglomeration factors would give their industrial development an autocumulative trendand would trigger further induction in a sort of artificial development of the industry, supported by an adequate infrastructure guaranteed by the consortia and the Cassa del Mezzogiorno.

Between 1957 and 1960, 3 ASI and 1 industrial nuclei were established, but over the next ten years a further 14 ASI areas and 28 industrial nuclei were established, with a rapid spread that affected the whole of Southern Italy. According to some calculations, this covered about $20 \%$ of the entire territory [8-13] (Figure 2).

The implementation timing, however, did not match the changes in the economic fordists and post-fordists processes, with the actual realization of the ambitious program of 'heavy' industrialization in the south being delayed when the metamorphosis of the productive system, delocalization in areas with cheap labour, and the disposal processes had already been put into motion. To this partial failure, already in essence in the operation, in the decades to follow spontaneous or planned urban transformations were induced thanks to the infrastructures built by and for the ASI, which have contributed to the urban disorder of a large part of the area. The result was an extensive mosaic of different territorial realities that, in particular in Caserta, defined a particular type of peri-urban area, with clear agricultural, urban, industrial and "operative" components (according to Brenner the new geographies of the urbanization phenomena, in which the "operational landscapes" are the crucial working engines of the system and should be considered as urban spaces involved in the urban policies and strategies) [20-22].

A sort of "new-urban" was linked to the industrial phenomenon, but has then selfreproduced and preserved autonomously. This is a dimension, both qualitative and quantitative, profoundly different from suburban and peri-urban phenomena, which 
is linked, for example in the United States, to the great cyclical crises of economy and industry [23].

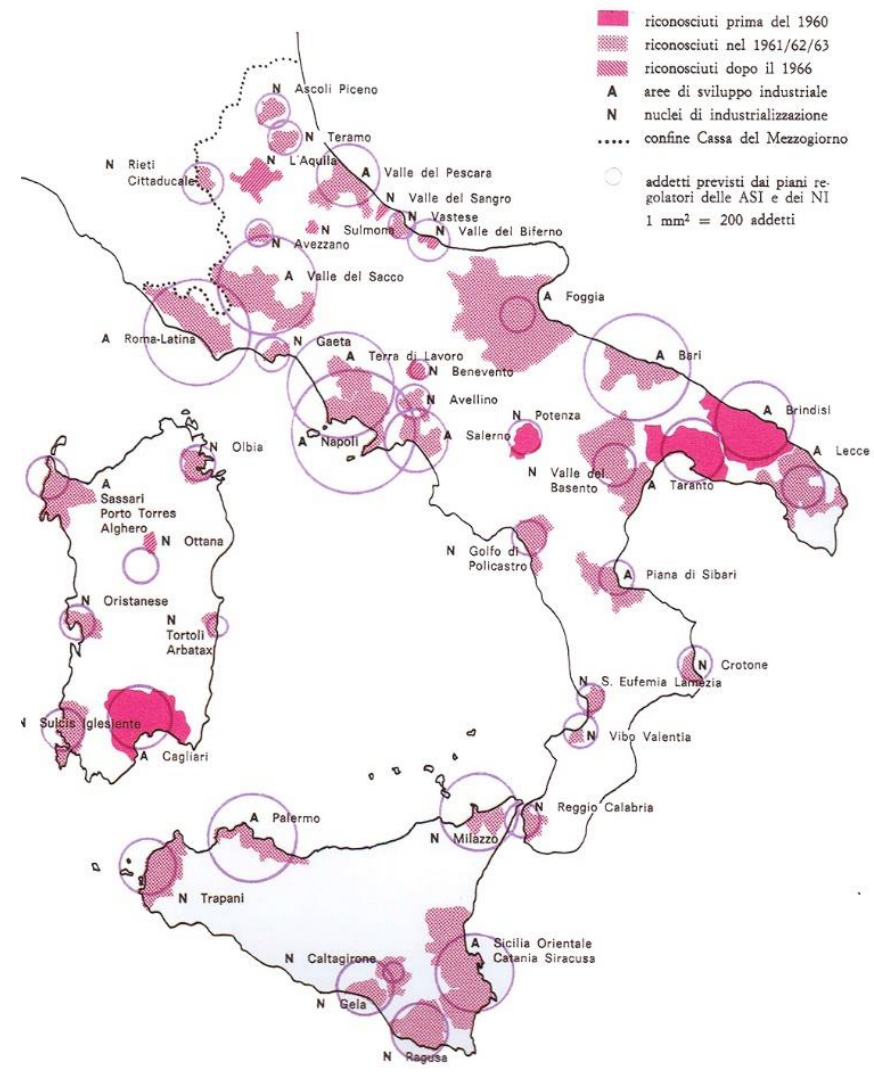

Figure 2. The industrial development areas (ASI) in 1972. Source: Urbanistica n. 57.

The productive industrial dimension, to be injected into the territories to reinvent their identity and project them as greater economic security towards the future, was a complex action that had different origins. In the urban environment and economic disciplines of those years, there were numerous experiences of "industrial concentration" in the international context that represented models of spatial planning and organization of industries on a regional scale. It is worth mentioning that those of the central manufacturing districts of Chicago and Los Angeles, as well as those that are today the "underutilized industrial district" of Detroit in the USA, the English ones of Port Sunlight, New Earswick, Letchworth, and Welwyn, the German ones of the Ruhr basin or the Wolkswagen complex in Wolfburg, as well as those of the great Russian interventions of Elektronowos, Leninakan (today Gyumri) and Magnitogorsk [12]. In Italy, from the point of view of design, in the absence of a consolidated experience, the technical operational references were constituted by manuals, such as the text by Frederick Gibbert, Town Design or The Architect's Manual, published in Italy by the National Research Council and edited by Mario Ridolfi, Mario Fiorentino, Bruno Zevi, Cino Calcaprina and Aldo Cardelli in 1946, or the book by Giorgio Rigotti, Urban planning. The technique, published in 1947. This transfer/adaptation of the experiences and techniques already consolidated elsewhere, found, in the urban culture, further references "justifying" the pioneering models rationalists and proto-rationalists who identified themselves in the attempts to overcome the urban, hygienic and functional crisis of the second industrial revolution. This was from the cite industrielle by Tony Garnier in the early 1900s, to the cité linéaire industrielle of Le Corbusier in the immediate post-war period, passing through the new urban and suburban dimension imagined by Wright in his Broadacre City in 1932, in which mobility, in the broad dimension of the prairie, was entrusted to individual transport and car mobility. This vision is today apparently anachronistic, but that, in fact, persists in the areas under study in this essay. In 
spite of this theoretical disciplinary support, made right also by the policies that regulated the hetero-directed industrialization of the south, the facts told a different story. This is evident not only from the point of view of the time lag and the delay with which this idea was implemented, while elsewhere it was already looking at the post-industrial dimension, but also from the point of view of the territorial forms generated. Today it is necessary to confront these forms, proposing eco-supported strategies of integration between functions (urban, industrial, rural), beginning from the "fossils" of the production, and from the unfinished plans. Considering these unfinished shapes, it is worth starting from the case of Caserta. In topological terms, the region [24] (in a post-metropolitan model, according to the geographer Edward Soja, the urban region is not clearly round nor city-commuted; it is characterized by new density gradients (of population and uses), transforming the relationships between the outer areas and metropolitan cores as an accelerated re-organization and restructuring of the geography of movements that define the spatiality of human societies [24]), which welcomed the urban territorial plan devised by the engineering company Teknè [6] and the ASI Caserta archive, has gradually changed into a mixture that could be metaphorically identified with the image of oil poured into water; it is a combination of territorial facts without amalgam, indifferent to each other even when they come into contact. This figure of the "oil city" is not only the result of the industrial plates planned by the Cassa per il Mezzogiorno (for ASI Caserta today there are 14), some of which are not at all or only partially settled, but also the establishment of a multiplicity of bodies, equipment, and infrastructures through sectoral logic and without coordination (the consortium is endowed with the original territorial development plan of the industrial development areas, approved with decrees of the president of the council of ministers (in the Italian Decreti del Presidente del Consiglio dei Ministri-DPCM) on the 16 January 1968 and 28 July 1970, and with a supplementary development and extension plan, approved with decree of the president of the regional council (in the Italian Giunta Regionale-G.R.), n. 14066 on the 29 December 1980. The first one, with the next variant (deliberation of Giunta Regione Campania-GRC, n. 4503 del 30/05/75) contains the forecasts and rules for the following agglomerations: North Volturno, Caserta Ponteselice, Caserta S. Nicola, South Caserta S. Marco, Marcianise, and North Aversa. The second one includes the planning and regulation of the following new agglomerations: North Cancello, Vairano Caianello, Matese, Mignano, Tora e Picilli, Teano, Sessa Aurunca, North Capua, and South Capua [25]). They are from operational objects for the management of waste flows, or those serving the building cycle, from further plates dedicated to production, to large hubs for trade (Centro Commerciale Campania, Outlet La Reggia in Marcianise, South Europe Interport), from the anonymous new residential expansion areas to real gated communities (such as the United States Naval Lodge of Gricignano D'Aversa) up to monads like the goldsmith complex "Oromare", close the industrial ASI agglomeration of Marcianise, the ancient complex of "La Maddalena" in Aversa, or the clusters in disposal within the urban fabric as the former Siemens in Marcianise, the former Tabacchificio in Sparanise, Texas Instruments in Aversa, and MACRICO in Caserta. To follow the elementary topology breakdown proposed by David Grahame Shane [26], this territory can be synthesized in terms of "enclaves" and "armatures". The enclaves, which we could identify, in this specific case, with production, urbanity, rural and drosscapes [21], are not only indifferent to each other (even when a plan, as in the case of ASI, should have taken care of integration), but they contend the soil, compete on the edges and in the wedges in between, and all three of these enclaves use the same structure, as follows: road axes, railway networks, commercial and entertainment attractors, the plot of the centuration, the historical centers, and the central cities for services of a higher rank (Naples, Caserta, Aversa).

Lands today demand an adequate interpretation and a common strategy that gradually can trace a new identity. The coordination between the ASI plans and the municipal ones has almost never happened, creating "fractures" in the territories, contributing to the separation of the industrial plates from the urban and rural contexts, creating industrial enclaves from the administrative point of view. This is a condition that has progressively 
worsened with the crisis and the closure of many activities since the 1990s. Today, several agglomerations are in a state of partial or total crisis. Some agglomerations have been identified by the plans and never realized, or subdivided only in a small part. Many areas are in a phase of decommissioning and public works, and the equipment are not realized or not usable. The relative plans were definitively approved approximately ten years after the law of 1957 (those of the ASI of Naples and Caserta, for example, were approved with of the DPCM of 19681), while the relative Consortia, which had materially drafted the plans, had been instituted in 1962. From the 1980s onwards, environmental issues and factors related to risk, pollution and the uncontrolled consumption of resources (water, electricity, soil) came into play. The water resources, for example, were localized and quantified, the best harvesting and distribution techniques were studied, always with a view of intensive use, also through desalination. The soil's perimeter and zoning was studied through often oversized development projections, while the studies around its protection and hydrogeological safety remained weak. Currently, the ASI and the industrial agglomerations that make them up demand regenerative processes that, starting from the condition of marginality and abandonment in which most of them are located, reinterpret them as new parts of the nearby cities, which are starting points for ecological operations, the integration of newly developed equipment, services, production activities and residential areas.

\section{Knowledge of the Territory. The Case of ASI Caserta and the Urban and Rural Contexts}

As previously introduced, the research investigates the context of Caserta, focusing in particular on some industrial agglomerations, in particular Marcianise and North Volturno. The specific characteristics of this area have been merged into the following systems of the urban metabolism of the places: the urban system, road connections, industrial, agricultural, potentially and effectively contaminated areas, and finally the water system. On the spatial dimension, their apparent interaction returns anything but a homogeneous picture, but on the contrary, it returns significant rarefaction and fragmentation in both perceptive and functional terms.

Within the PURE research, these systems define a field of investigation that focuses on a vast area of peri-urban, largely the result of industrial development planning initiated by the Cassa per il Mezzogiorno. The current conformation of the places appears "characterized by the presence of operational landscapes [27] such as decommissioned productive activities, landfills, illegal uses, agricultural inserts and residential areas as well as major infrastructure axes", and it has been gradually outlined "on the planned structure of industrial development areas that, since the 1960s, have defined the form and identity" [28].

Currently, the identity matrix of these places appears compromised and overshadowed by phenomena of a decline largely attributable not only to the mutation of the production cycles, to phenomena of the abandonment of the dense farming and related activities, but also to the economic crisis and critical issues related to the waste cycle, their illegal spills, and the practices of illegal building.

Over time, these events have defined the boundaries of what is known today as the Land of Fires, a spatial and figurative mosaic of fragile, marginal ecosystems, without rules and form, subjected to continuous transformative phenomena and decay. The spaces therefore decline, and the waste territories are residual, neglected and inconsistent with the peri-urban metabolism of these places [29].

By going beyond and overturning the traditional negative meaning reserved to these spatial spheres, the reversal of the course foresees their rethinking in terms of "reservoirs of opportunities from which to rethink urban strategies and put forward credible hypotheses to rebalance the territory of Caserta" [28].

In this sense, what is reported within the territorial plan of coordination of the province of Caserta (PTCP) is relevant, which proposes a reinterpretation of these areas through the concept of "denied territory", namely, "areas belonging to both the urban system and the peri-urban system, without a defined function and marked by obvious signs of degradation" [30]. 
For the city of Caserta alone, the PTCP has identified 194 sites with an overall extension of 483 ha (out of a total of about 5000 ha for the entire province). In particular, the "denied territories with environmental potential" are identified (landfills, disused quarries, critical areas of the peri-urban territory or pertaining to large infrastructure), which on the territory of Caserta occupy an area of about 2600 ha, and for which the plan provides for the restoration and renaturalization of the pre-existing nature. The "denied territories with settlement potential" are the critical areas of the urban territory that extend over an area of 2450 ha, and for which urban restructuring with residential, productive and service uses is planned.

These assumptions, however, do not find actual practical feedback in the current practice and territorial configuration due to the complete lack of local policies aimed at orienting the strategic action and vision for the future of these areas that, only partially, have been converted.

In this light, the mapping process (as described in Section 6: Mapping the territory. The cartographic palimpsest of PURE research) has been fundamental for an accurate analysis and the return of an innovative rereading of them, with it forming the basis for an in-depth investigation on which to focus gazes, and collect information and data to develop an integrated system of intervention strategies and actions.

\section{Eco and Nature-Based Solution for New Lands}

For the selected industrial agglomerations, the research aims to identify some EIS or $\mathrm{NbS}$. The latter result from an analysis and from enhancing of the relationships, at the various scales, that exist between the agglomerations of the industrial development areas with the fabric of the consolidated city, the infrastructure system, that of the agricultural plots and potentially contaminated sites that wind around them. Within the proposed research path, the EIS or $\mathrm{NbS}$ are drawn from the literature or are already implemented in urban contexts with characteristics similar to those under investigation.

Within the regenerative dynamics to be applied to the compromised industrial areas, the concept of EIS or Nbs finds a fertile place and it is the main output of the co-creation process mentioned above.

In the current literature on the subject, there are various definitions relating to the term eco-Innovation. The main difference between those of less and more recent elaboration lies in the fact that the former focused essentially on the assessment of environmental impacts [30-32]; the latter, on the contrary, included not only ecological, but also economic and social aspects, with the triad being the basis of the concept of sustainability.

Therefore, the most shareable one has been elaborated by the European Community in 2012 in which, for eco-nnovation, they intend the following:

"all forms of innovation-technological and non-technological-that create business opportunities and benefit the environment by preventing or reducing their impact, or by optimising the use of resources. Eco-innovation is closely linked to the way we use our natural resources, to how we produce and consume and also to the concepts of ecoefficiency and eco-industries. It encourages a shift among manufacturing firms from end of pipe solutions to closed-loop approaches that minimise material and energy flows by changing products and production methods, bringing a competitive advantage across many businesses and sector" [17].

The possible eco-innovations include those supported directly by natural processes, the nature-based solutions $(\mathrm{NbS})$, namely, solutions that are "inspired and supported by nature, which are cost-effective, simultaneously provide environmental, social and economic benefits and help build resilience. Such solutions bring more, and more diverse, nature and natural features and processes into cities, landscapes and seascapes, through locally adapted, resource-efficient and systemic interventions" [19].

Nature-based solutions are therefore defined "as actions to protect, sustainably manage, and restore natural or modified ecosystems, that address societal challenges effectively and adaptively, simultaneously providing human well-being and biodiversity benefits" [33]. 
$\mathrm{NbS}$ is an umbrella concept that includes a series of ecosystem and site-specific approaches that are implemented individually or integrated with other solutions, combining economic, governance and social innovation, and providing direct environmental, social and economic benefits to the contexts in which they apply [33]. Overstepping the antithetical relationship between the natural and anthropic components, the $\mathrm{NbS}$ allow to define shared lines of action in terms of urban regeneration, ensuring the improvement and protection of natural capital, risk mitigation and sustainability of the intervention. In addition, the use of EIS and $\mathrm{NbS}$ for the regeneration of marginal spaces, annihilated by degradation and contamination, is strongly supported globally for reasons attributable to economic convenience and the ecological and social dimension.

The solutions, to be developed in the last phase of the PURE research project, in addition to their technical and technological specificity, appear innovative, especially because they are designed for a context where territorial fragmentation, characterized by the total absence of a coherent and adequate soil design, dynamics related to the risk and contamination of natural matrices, the agricultural vocation, denied by the presence of a dense texture of uncultivated or abandoned fields, and a water system that is strongly compromised, represent the dominant condition and the frame in which these large territorial portions are placed "in suspension".

The development of the solutions starts from the previously mentioned "systems" of the urban metabolism (urban fabric, connections, industrial fabric, agricultural plots, potential or effectively polluted areas, water system).

With respect to these systems, the research identifies for each of them guidelines that can be translated operationally and subsequently in some EIS or NbS. In particular, the action for the first "urban fabric" system, in addition to providing restoration and integration between the consolidated city and the surrounding suburban landscape, will be oriented to the prediction of measures to stem the presence of the polluting component due to the proximity to the industrial plate. In this sense, in addition to the provision of soft mobility, through the provision of cycle/pedestrian paths, further mitigating measures will be considered with the aim of reorganizing and implementing the green component in these places.

Therefore, in addition to the prediction of vegetative or mixed systems (plant and artificial ones), also with the function of controlling the visual permeability with respect to the industrial manufactured products, concealing the view on the obsolete and enhancing those of significant architectural value, it will also proceed to reconnect the green areas present, of different types (public, uncultivated, agricultural), through the provision of green corridors, equipped filter areas and the enhancement of abandoned plots.

The second "connections" system, in addition to contemplating a hierarchization of vehicle, bicycle and pedestrian flows within and around industrial areas, will be oriented towards the introduction of active technologies aimed at the production of kinetic energy and ecological environmental connections.

Within the "industrial fabric" system, in addition to the visual permeability control solutions mentioned above, there will also be solutions for the mitigation of acoustic impacts through the insertion of integrated shielding systems, which are made with both plant and artificial elements (such as a vertical mobile garden or green noise barriers), with the expected innovative reuse, even temporary, of the industrial plants of a particular value.

The "agricultural plots" system refers to the dense texture that creeps between the urbanized and the industrial plate.

In relation to these areas, the research proposes a rethinking of the same in regenerative terms, going beyond the concept of agriculture as a practice aimed at the mere production of primary goods and declining it in systemic terms as a link between the place of production and the system of territorial relations that make it a resource; in entrepreneurial terms, this is through the activation of innovative farms; in perceptive terms, this is with respect to the value that the agricultural soil can have if it is related to concepts such as short chain and 
$\mathrm{km} 0$ production; in terms of the territorial vision, this is promoting integration between agriculture, production and multifunctionality. The more complex system "potential or effectively polluted areas" will provide the introduction of remediation strategies favoring those nature-based where possible (such as phytomedia), integrated interventions (hard and soft) in conditions that are more compromised, promoting at the same time the perceptual recomposition of the landscape, in an improvement key. The latest "water" system will insist on the use of solutions aimed at the decontamination of water (such as the creation of wetlands), as well as the control, collection and reuse of meteoric water through the predisposition of green streets, bioswales and raingardens.

The EIS or NbS have the aim of addressing the regeneration process of the sample areas providing for the reconnection and stitching with the various structural components of the territory, both from a functional and ecological point of view, while mitigating and offsetting the interrelationships between the different systems. The proposed definition therefore makes it possible to reread and reconsider these territorial passages as preferential trigger points for the implementation of regenerative practices in which to start a reversal of the traditional approaches confined to short-sighted sectorialisation, moving them towards a more sustainable and circular perspective [34].

The merging of EIS and Nbs defines territorial and spatial strategies. The latter draw operational lines for the triggering of profitable regenerative processes in the areas of intervention investigated, to improve the liveability and quality in the view of urban metabolism. The operation of synthesis and integration of the aforementioned strategies will take place in a "masterplan", intended here as a tool made of images, maps, simulations, diagrams and assessments that are able to combine the form, standard, technology, present and forecasting practices [35]. In this sense, the masterplan will be the result of a complex process of interactions between urbanist, specialist knowledge, public client, social actors, economic actors, citizens, and current practices (agricultural, functional, use, etc.). This is a tool, therefore, able to maximize the spatial and functional quality of the urban project, while ensuring the dimension of sustainability, functionality and optimal habitability [35].

\section{PURE Productive and Urbanism Resources. Eco-Solutions for New Lands}

With regard to the premises, the PURE research project moves so as to integrate functions and define a "new urban". The research is inserted, in fact, within some consolidated research and experimental paths on peri-urban territories as an opportunity to stimulate the experimentation of eco-innovative methodologies and practices to rethink the role of industrial areas at different territorial scales. The disposal, abandonment and degradation areas represent crucial contexts in the processes of urban and peri-urban redevelopment, which are focused on the consumption of "zero" soil, the spatial and ecological quality of the project, and a regenerative approach to the territories [36-39]. The PURE project, although ongoing and strongly multidisciplinary, has defined in its first results a knowledge framework on industrial development areas, in particular in the regional territory of Campania and Caserta. In the preliminary and exploratory phase, the main consideration was given to the economic, social, infrastructural factors, and the relationship with the natural, rural and man-made landscape of the settlement of these industrial complexes in urban contexts, from the early 1960s. As previously stated, the research has identified the context of Caserta as its experimentation area in which, acting in collaboration with the consortium ASI Caserta and the department of territorial planning of the Campania region, it has elaborated a reconstruction of the territorial system through a multiscalar set of implementable maps, using the geographic information system (GIS) program for the collection of the interpretative parameters that allow for the reading and understanding of its intrinsic complexity. The analytical framework was completed and supported by an archive research phase at the ASI consortium in Caserta, with the collection of urban development plans and projects that have followed over the years, and have defined the structuring characteristics of the current industrial settlements. The interdisciplinary approach underlying the research, together with the use of models related to environmental 
and geographical sciences, will be fundamental in the next experimental phase of the project. The latter will provide for the integration of the design strategies with the issues related to urban planning, nature-based and eco-innovative techniques, and technologies for the environmental and ecological redevelopment, also present in the current literature on the subject. The experimental approach will therefore elaborate on the planning strategies in the defined sample areas, and circumscribed territorial contexts in which the co-presence of different problem conditions makes it particularly interesting to suggest EIS, spatially and functionally impressing. Therefore, the project examples will be aimed primarily at generating a new quality public space, consisting of functional and interconnected places, intended as a primary common good, also in terms of new habitability and fruition in times of a pandemic. A sort of urban "wedges" that, by crushing the drops of the oil city, penetrate the edges of these industrial areas, implanting new urban functions (residence, tertiary, commercial) that are compatible with renewed industrial types.

\section{The Methodological Framework}

The methodological framework (Figure 3), inherent in the process of the mapping and the development of design strategies, has been articulated in different steps structuring a recursive process. It describes and explains a flexible and adaptive approach to the territory and its understanding.

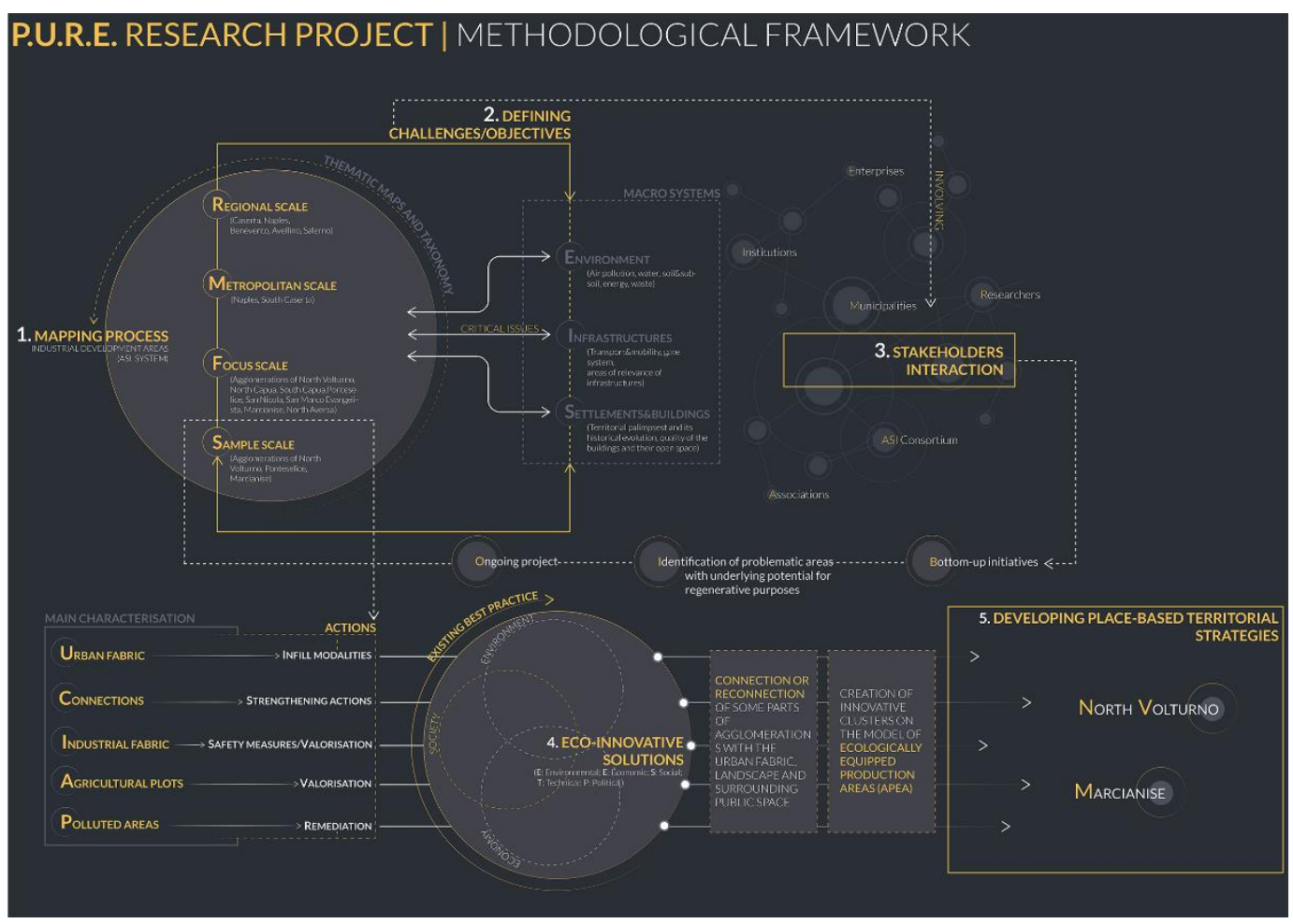

Figure 3. Methodological framework. Source: PURE team.

The recursive approach is particularly suitable for investigating the metabolisms of declining territorial realities and their reactivation modalities, as has already been experimented with in European research projects [40], such as REPAiR (REsource Management in Peri-urban AReas). Going Beyond Urban Metabolism is a research project in which the authors of this essay have also worked, with funding from the European Union's Horizon 2020 research and innovation program under grant agreement No. 688920. It is aimed at identifying eco-innovative scenarios, defined through the cooperative planning of the territory in cooperative and shared form (Living Lab). For further information, please see (http:/ / h2020repair.eu/, accessed on 13 May 2021). The methodological processes of 
the cyclical matrix allow to reshape the observations and evaluations that emerge both from a multiscale reading of the territory, and from the elaboration of regenerative and place-based approaches. The iterative logic allows, during the process of the reading and understanding of industrial and territorial dynamics, to orient the design action with respect to problems that could emerge at any step of the process, thus promoting the development of place-based strategies with respect to the specificities of the contexts under investigation. Within the methodological framework, the first step consists of a spatial analysis and subsequent mapping process of the system of industrial development areas, with all of the elements connected to them at various scales, intertwining on the territory. The objective of the mapping process, through a new rereading and understanding of the territory, is two-fold, as follows: on the one hand, to investigate the current condition of crisis and abandonment of the large industrial complexes in which, in some cases, it is still possible to see a defined identity matrix; on the other, to analyze the spatial relations that exist between the industrial plates and the residential, agricultural, natural and interstitial areas, and the hydrographic network, which is mainly polluted, and the state of the soil and its uses.

The mapping process is configured as multiscale [41], then it identifies different scales of depth, which are attributable to a regional, metropolitan focus, and the more detailed last one is definable as the sample. Each proposed scale provides a spatial reading for the morphological, natural, physiographic and land use "systems", and the buildings. Specifically, the regional scale (Figure 4) returns, in a systemic vision, the complexes of the industrial development areas found between the provinces of Caserta, Naples, Avellino, Benevento and Salerno, which then in the metropolitan scale are reduced to the territories of Naples and South Caserta. The focus scale allows to better read and understand the spatial characteristics of these places, intercepting a particular type of peri-urban territory [38] composed of agricultural urban and industrial elements, and in which the industrial agglomerations of North Volturno, North Capua, South Capua, Ponteselice, San Marco Evangelista, Caserta, Marcianise, and North Aversa stand out. Finally, the scale of the sample identifies contexts of greater depth, such as the preferential territorial portions in the municipalities of Marcianise and North Volturno.

To this end, the first mentioned urban metabolism systems have been merged, in an exemplary logic, into three macro-systems related to the environmental, infrastructural and evolutionary issues of the territorial fabric and palimpsest, with particular attention to the quality of the valuable architectural elements, the built and the open space that are present.

The first of the three macro-systems can be ascribed to the environmental sphere, including the different anthropogenic and natural factors and elements that determine it. In this light, explicit reference will be made to the issues relating to the water system, soil and subsoil, energy, the dynamics related to risk, air pollution, and that produced by waste; the latter is criticality particularly rooted in these places, especially with regard to the problems of illegal spills. The risk condition affects both the areas in which industrial plants insist and those immediately adjacent to them, involved in the contamination processes of both natural matrices (air, surface and underground water networks, soil) and the anthropogenic component, this is useful in relation to dangers such as toxic emissions and explosions. For these reasons, it is essential to mitigate this condition through measures that ensure the safety or reclamation of the places so that they are usable for the established communities. The achievement of this objective therefore includes the assessment of possible solutions, which, acting on the specificity of the contexts, ensure a mitigation of the environmental problems encountered and their impacts, restoring the lost environmental balance and ensuring greater landscape quality and higher safety.

The second macro-system regards the infrastructure and accessibility issues of the investigated areas. In particular, within this section, criticalities of the current system of the mobility and the transports are analyzed, together with the inadequacy of the access routes to the areas, as well as the presence of marginal areas blocked or pertaining to infrastructure 
that, often and improperly, are subject to illegal spills or that in any case are in a state of significant neglect. Considering the negative impacts of the inefficiency of an appropriate connection and transport system, the action strategy is oriented to rethinking traffic flows within the industrial and urban context, in favor of more sustainable mobility. The latter, in particular, could be obtained through a hierarchization of the vehicular, cycle and pedestrian flows, through shared and intermodal transport systems [34], and through the prediction of ecological routes and the forestation of existing roads. Therefore, it is crucial to strengthen the link between the existing infrastructures together with the regeneration of those neglected territorial portions that wind along and within the infrastructure network.

PURE | Productive and Urbanism Resources

Eco-Solutions for new land

\section{METROPOLITAN SCALE}

\section{CASE REPORT | INDUSTRIAL DEVELOPMENT AREAS}

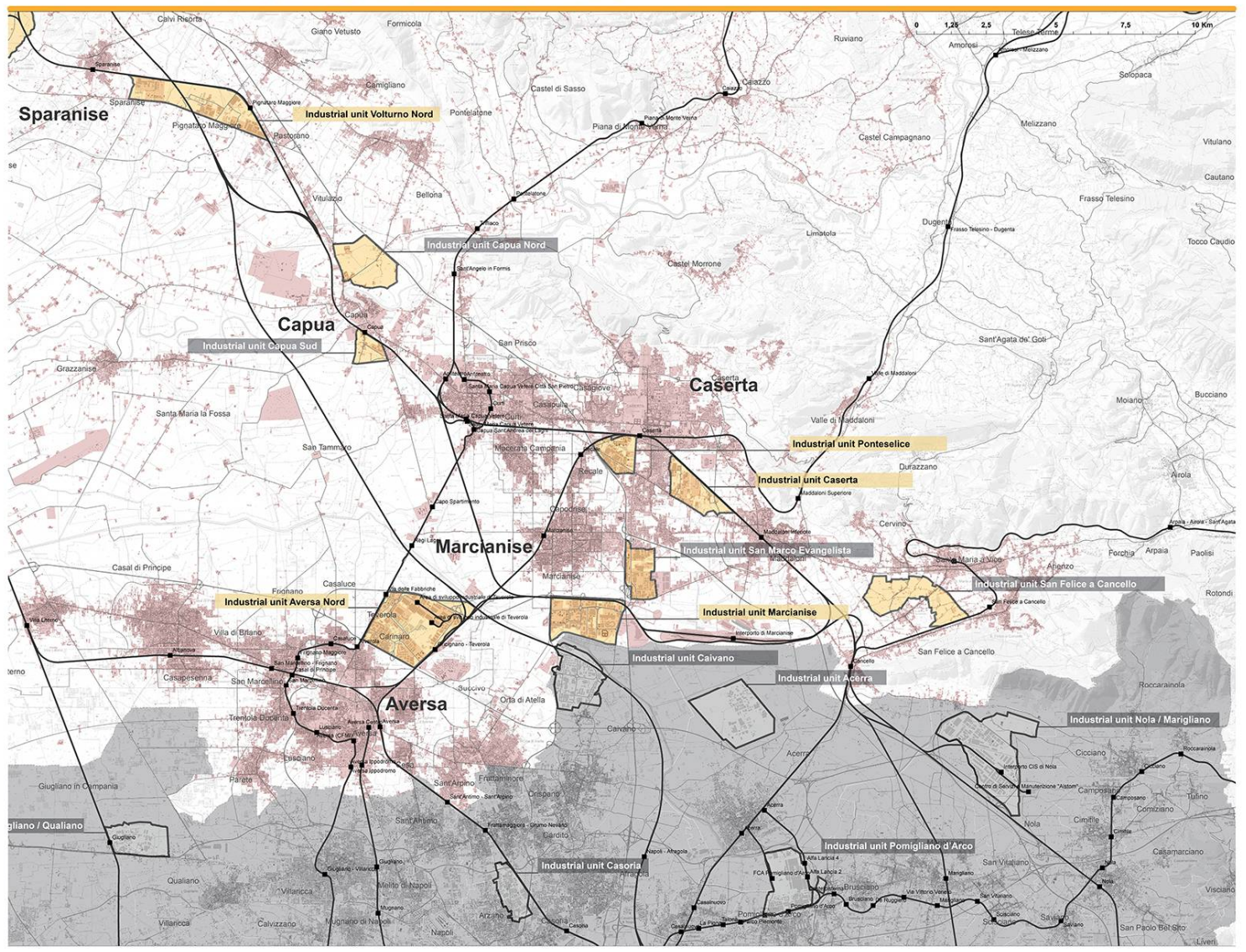

\section{Legend | Territorial analysis}

Industrial development areas

Industrial units
Caserta province

Industrial units
Urban fabric

Continuous and Discontinus and urban fabric
Trasportation units

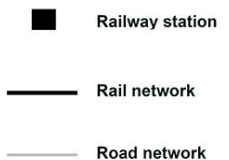

Figure 4. ASI Caserta: regional scale map. Source: PURE team.

Finally, the third macro-system concerns the built and the open public space. Going beyond the consolidated conception of the productive settlement as a peripheral place and 
undisputed source of pollution, often these areas underlie a non-negligible identity matrix, enriched by the presence of valuable architectural artifacts (such as Kodak, Siemens, Pozzi and Olivetti buildings) destroyed, to this day, by decay and neglect. In this sense, the action translates on these elements, defining objectives for improving the quality standards of buildings and open space, increasing the comfort as well as the inclusion and dialogue with the surrounding environment through the provision of paths that enhance the presence, and through actions that provide for innovative reuse.

With respect to these macro-systems, the following table shows some merged data for the focus area of Marcianise and North Volturno, comparing them with the provincial dimension (Figures 5 and 6).

From these data and the relative mapping, some relevant aspects of the focus areas can be inferred, the following in particular: 1 . a high density, absolute and compared to the provincial average, of "contaminated lands"; 2. a high density also of "transport units"; and 3. the presence of large rural areas despite the strong presence of industries.

The third step of the proposed methodology concerns the interaction with potential stakeholders. The interactive and co-creation process finds, within issues related to the reactivation and relaunch of these parts of the city, fertile feedback. In the field of urban planning, overcoming the mere point-of-reference and sectoral approach favors the launch of a new dimension of the land project, and in an extensive landscape view, placing it in an integrated and intersectoral operational perspective aimed at recovering the strategic values and identities of these territorial realities.

Within the PURE research project, the co-creation process focuses on the fruitful interaction between the institutional, private and third sector decision makers. The systematization of the collected information, following the comparisons with the subjects cited, has allowed not only to orient the mapping process, but above all will be useful for the development of actions and solutions for the recovery and regeneration of the contexts, as foreseen by the last step of the methodology.

\begin{tabular}{l|cc} 
Topics & $\begin{array}{c}\text { Topics surface in Focus Areas / } \\
\text { Focus Areas Surface } \\
{[\%]}\end{array}$ & $\begin{array}{c}\text { Topics surface in Focus Areas / } \\
\text { Topics in province of Caserta surface } \\
{[\%]}\end{array}$ \\
\hline Agricoltural areas & 43.2 & 0.4 \\
\hline Industrial units & 33.7 & 19.8 \\
\hline Urban fabric & 7.2 & 0.7 \\
\hline Transport units & 15.9 & 5.1 \\
\hline Contaminated lands & 1.7 & 15.2 \\
\hline
\end{tabular}

Figure 5. Incidence value of study areas with reference to provincial values.

\begin{tabular}{l|cccc} 
Topics & \multicolumn{3}{|c}{$\begin{array}{c}\text { Surface in Focus Areas } \\
\text { [hectares] }\end{array}$} & $\begin{array}{c}\text { Total Surface in Focus Areas } \\
\text { [hectares] }\end{array}$ \\
\hline Agricoltural areas & Operating & Abandoned & Reclaimed & 699.9 \\
\hline Industrial units & 670.5 & 29.4 & - & 546.1 \\
\hline Urban fabric & 495.0 & 51.1 & - & 116.4 \\
\hline Transport units & 116.1 & 0.3 & - & 256.7 \\
\hline Contaminated lands & 256.7 & - & - & 19.0 \\
\hline
\end{tabular}

Figure 6. Focus areas-mapping data.

\section{Mapping the Territory. The Cartographic Palimpsest of PURE Research}

The fulcrum of the methodological frame, which is also useful to guide the regeneration project, is the mapping process. The multiscale analysis process of the territory 
on which the subsequent elaboration of the thematic maps was based allowed to read the transformations that over time have undergone the territories with a rural vocation to accommodate industrial functions. The inception, development and dissemination of territorial information systems (in Italian Sistemi Informativi Territoriali-SIT) have led to profound changes in the working methods of the disciplines that study the territory in its various spatial and immaterial forms. The technology based on the GIS (geographic information system) software and the increasing availability of spatial data on open source platforms has made it possible, in addition to the possibility of the interchange of data and information, to define and structure a scientific approach based on multidisciplinarity [42]. This methodological process allows, on the one hand, to create and structure cartographic databases from available information, and on the other, to create new information from the existing data or creating new ones. It is clear that this methodological approach is based on a procedural, multidimensional and multidisciplinary work in which the individual, cartographed and georeferenced elements, enter into a relationship creating a unique information network, which is implementable and searchable. In this light, SIT are an essential tool for visualizing, interrogating and analyzing spatial data sets. The mapping process, developed in the GIS environment, represented the cartographic palimpsest in which the different research activities of the PURE project were merged. The main objective was to create, on a computerized platform, a mapping system that was able to provide technical/scientific support and a precise mapping survey methodology at the same time. The result obtained is represented by a series of quantitative and qualitative analyses on a large part of the territory of Caserta and its industrial units. Another aspect that has determined the choice to carry out mapping in the GIS environment is the possibility to return this cartographic information shared, in the future, on open source platforms. From this point of view, some web platforms are paradigmatic, including those that are based on open source software such as OpenStreetMap or Wikimapia, which allow users to build "geographies" information aimed at collecting geo-referenced data on various topics and sharing them with communities. In light of these considerations, the mapping carried out with the GIS tool makes cartographic information available not only to the scientific world, but also to public administrations and citizens through "the set of approaches and practices that make GIS a tool available and accessible to all those interested in taking part in decision-making processes" [43,44]. The use of digital technologies and, in particular, of these software systems has allowed for, in the field of the PURE research, the creation of a geo-referenced spatial mapping database to expand the knowledge base to analyze the spatial planning of industrial development areas in the province of Caserta. From the beginning, a mapping system has been developed that can be implemented and aligned to current or future proposals. This is a system, therefore, not an end in itself, closed and "static", limited to collecting and storing information, but able to adapt to the various stages of research, ranging from mapping data to sharing. The aim was to define "thematic" cartographies that, starting from cartographic data, could support and facilitate the reading of the elements that distinguish these areas. This is an interpretation that we could define as multiscale, which is aimed at analyzing and understanding the specificities, the values, and the criticalities to the various scales of investigation. It is in this scenario that the GIS tool operates and provides support to research activities. Through the various geoprocessing applications (intersecting, spatial join, overlapping), it was possible to create a complex system of geographic data specific to each level of information. This process was the starting point for the realization of the thematic maps of reference in which the GIS tool has allowed to integrate, reformulate and implement the databases. As mentioned above, the mapping process is based on a methodological and procedural work, which can be summarized as follows: an initial phase based on the identification and collection of the data to be included in the GIS system; a second phase aimed at inserting the data on the software platform for the creation of geo-relational databases; and a third and final phase dedicated to the representation of the data through implementation, always in the GIS environment, of thematic maps that will be the element of representation of geographic information. An 
important aspect worth emphasizing is that, within the PURE research project, in addition to the shapefile that forms the basis of the work in the GIS software, different types of raster files have been used. These files have been used not only as a map base (regional technical map of the Campania region), but at the same time have allowed to verify, update and create new sets of cartographic data. In particular, through the maps provided by the Military Geographical Institute (in the Italian Istituto Geografico Militare-IGM), it was possible to retrace and reconstruct, starting from the 1950s, the development of the settlement and infrastructural system of the study areas, thus leading to a mapping of the entire territory. As previously stated, the purpose of the mapping was to provide useful support for reading the areas of industrial development and the surrounding landscape in which they are located. For this reason, four detailed "scales" (level of detail-LoD) have been identified and defined to analyze the complex system of industrial development areas and the agglomerations that constitute them. Four reference scales, consisting of regional, metropolitan, focus and sample, that, for their own characteristics and for the treated themes, have allowed to use, in the GIS environment, different typological datasets. This cross reading for "cartographic scales" has allowed to select the available information depending on the LoD that is wanted to consult. Despite these levels intercepting very dissimilar territorial portions, the process of mapping on the GIS platform has allowed for the integration of the different databases, available or realized, in order to reproduce a picture that is as homogeneous as possible.

The regional scale reports, in a global view (reference scale 1:120,000) and on a satellite basis, the industrial agglomerations present in the province of Caserta, with the aim of providing the following two series of information: the territorial classification of the industrial development areas of the province of Caserta in reference to the infrastructure network; and quantitative data on the size of the areas that can allow its comparison. If with the regional scale, there is the need to have a first look at the ASI areas and to frame them in the regional territory, it is with the successive scales of reference, metropolitan, focus and sample, that there is a more in-depth cognitive approach aimed at the identification and analysis of themes that are closely interconnected with those that constitute the geomorphological elements structuring the territory. It is with the creation of these maps that cartographic information is enriched with new levels of information.

The metropolitan scale, with an extension of $940 \mathrm{~km}^{2}$, returns a reading of a territorial framework particularly representative of the understanding of the spatial complexity in which the system of ASI is located. In particular, within the PURE research project, the metropolitan scale is restricted to the industrial agglomerations falling within the province of Caserta and, in part, of Naples, highlighting a mosaic of heterogeneous spaces in which urban, infrastructural, rural characters, peri-urban and environmental intersect with productive areas. In this part of the territory the great infrastructural arteries (A1 and A30 highways, SS7, SS6, E45), the secondary roads, as well as the railway connections (high-speed train station Naples-Milan, Ferrovie dello Stato Mercitalia railway and the ordinary railway network), intertwine with the hydrographic network (river Volturno to the north and Regi Lagni to the south). In the interstices of the infrastructural and water network, it could be insinuated that they could be defined as the places of the waste (abandoned agricultural plots, abandoned industrial complexes, contaminated soils, operational landscapes linked to the waste cycle), with significant consequences in terms of risk as well as denial and concealment of the territorial palimpsest of these places, particularly representative of its environmental, historical and settlement characteristics. The analyses of this scale of representation have led to the use of different sources of cartographic information. Many of the analyses were developed starting from the map database created by the National Institute for the Protection and Environmental Research (in the Italian Istituto Superiore per la Protezione e la Ricerca Ambientale-ISPRA) for the realization of the nature map of the Campania region [45]. This base has allowed to extrapolate different layers of analysis (artificial surfaces, agricultural areas, forests and, semi-natural areas, wetlands and water bodies) and to create, through geoprocessing 
applications, the following four different thematic maps: environment, land, water and ecosystem services, and settlements and buildings. Another difference with the regional is that, for both the metropolitan and the focus scale, the regional technical charter (in Italian Carta Tecnica Regionale-CTR) has been used as a map base, superimposed on a threedimensional model of the ground, made through a digital mesh of triangles arranged in space (triangulated irregular network-TIN), which offers a more accurate representation of the orographic and physical-environmental system of the territory.

As for the focus scale, in the impossibility to use map databases such as "Urban Atlas" of the European project Copernicus, whose coverage does not include the territory of Caserta and the same nature map that has a maximum representation scale of 1:25,000, the mapping work has been developed from scratch, giving the possibility to elaborate a structured and detailed informative database, which is usable for each area of investigation and able to be used for the next phase of study of the sample with a LoD equal to the scale 1:1.000. In order to obtain this level of detail, in addition to using informatic systems (satellite images, cartography, open data), the working group carried out intensive onthe-spot inspections to verify the accuracy of the data, to integrate information and draw new information layers. The mapping processes focused on the industrial agglomerations of Marcianise and North Volturno and, extrapolating them for a thematic mapping with respect to land (Figure 7), settlements and building (Figure 8), transport infrastructures (Figure 9), and water system (Figure 10).

In the first one, the focus area has an extension of $10 \mathrm{~km}^{2}$, and is bordered by the former industrial plant of Siemens, the water infrastructure of the Lagno Vecchio, the commercial platform of Campania Center, and finally from a green crown composed essentially from green public and agricultural plots. In the central part, ASI and other elements characterizing the agglomeration, including the abandoned land; contaminated, unused, but planned, industrial plots; and waste treatment facilities.

The focus area with the industrial agglomeration of North Volturno has an extension of $6.2 \mathrm{~km}^{2}$ and includes the entire ASI area, which extends to the municipality of Pignataro Maggiore. The area identified is crossed by important infrastructures such as the railway line Naples-Cassino-Rome (FS), high speed, the State Road 7, better known as Via Appia, the State Road 6, or Casilina, and E45. In addition to industrial plants, in this case too, agricultural soils are found, cultivated with arable land and fruit trees, or in a state of neglect and degradation, often also contaminated because they are placed close to the industrial plants. Among these, it is possible to identify unused industrial lots but, according to the provisions of the ASI regulatory plans, they are intended for industrial activities. Within the focus areas, "sample areas" have been extrapolated, of greater detail and attributable to a scale 1:2000, which are useful to orient the next project action. The samples of the industrial agglomerations of Marcianise and North Volturno have an extension of, respectively, 2 and $5.4 \mathrm{~km}^{2}$. A further informative step has been reached in the sample. To the data acquired from the previous investigation phases in this level, the information has been merged in cascade with all the collected information. With the geoprocessing, a "table" join has been carried out that has allowed to integrate, to the existing information, all the data supplied by the ASI Consortium, relative to the industries present in the industrial areas. With reference to the data that have emerged from the analysis and the mapping process, the sample of Marcianise emerges as a territory with an agricultural vocation that insinuates, as a sort of filtering area, between the urban center to the north and the industrial agglomeration to the south.

This territory constitutes an ecological transverse corridor that allows to avoid welding between the parts. Another element that emerges from the analyses at this scale is the presence of the following three areas identified by ARPAC as polluted sites and destined for reclamation: in addition to the already known Eco-Bat and Ex Siemens areas, the regional agency's investigations also identified the lot north of the football field as a polluted site. 


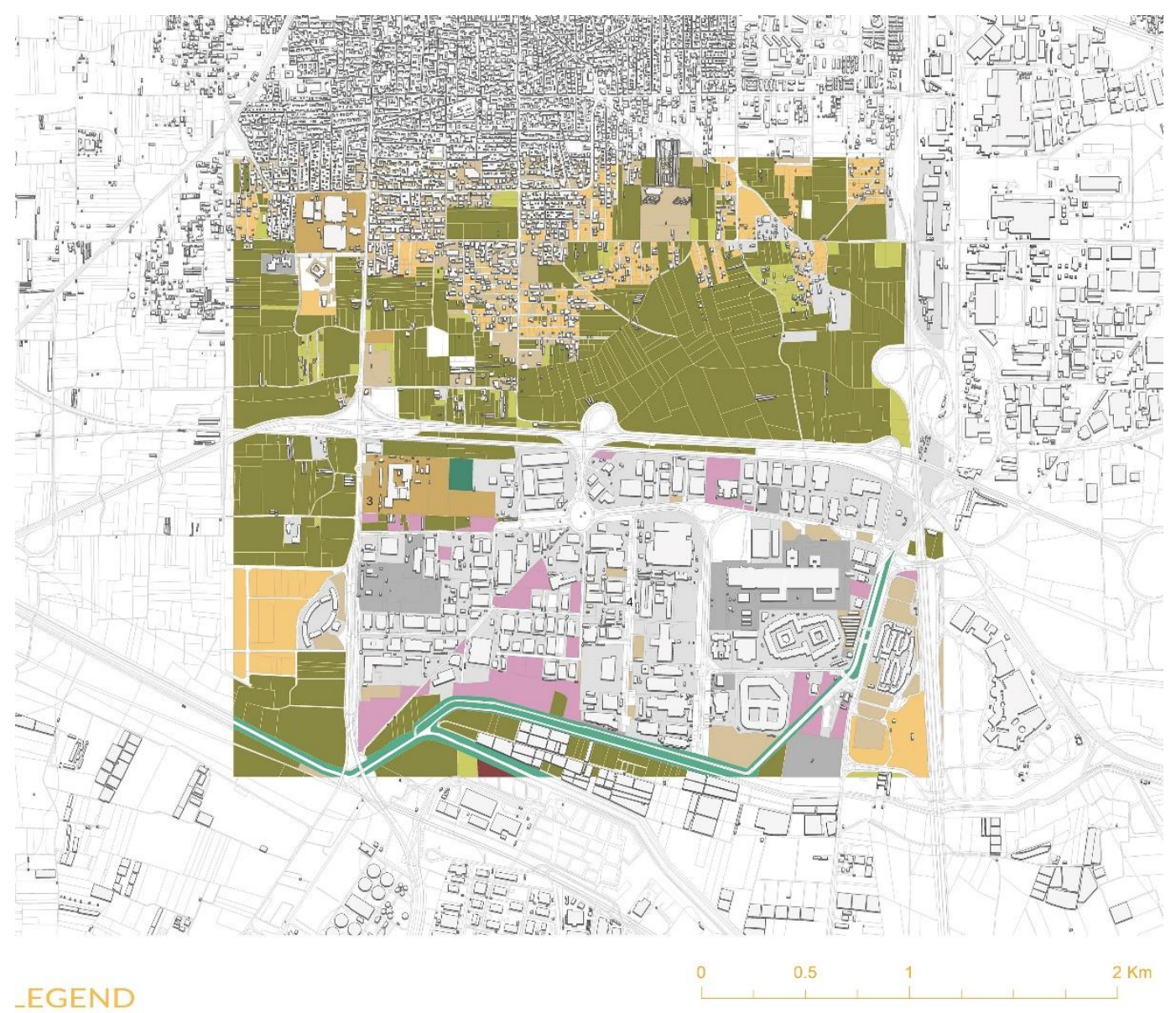
Abandoned agricultural lands
Abandoned industrial parcel
Abandoned soils
Contaminated lands
Operating agricultural lands
Operational waste Land
Productive sites
Reclaimed soils
Riparial zones
Unused and planned industrial parcel
Unused and planned parcel
Urbanized areas

Figure 7. Marcianise: focus scale. Land. Source: PURE team.

The sample of Sparanise, within the industrial agglomerate of North Volturno, intercepts different elements and types of fabrics, so it is very dense. In addition to the infrastructure system, consisting of the Naples-Cassino-Rome railway line (FS), the highspeed railway, the Via Appia and the highway, which constitute real barriers within the territory, there are cultivated or abandoned agricultural soils, and whole plots intended for greenhouse production. The industrial area is bordered by the canal Rio dei Lanzi. The central part of the sample areas contains a large filter belt, also agricultural, and that is the separating element between the urbanized area and the industrial area where there is the presence of dismissed and active industrial plants, such as Calenia Energia, designed by Frigerio Design Studio, Co.el.me s.r.l., G-R PIPE and the roofing factory Cantile GD Giordano. In addition to this, there is the presence of abandoned soils, abandoned green areas among residential and industrial buildings, as well as the presence of precious archi- 
tecture and industrial artifacts, such as the Pozzi industrial complex, designed by Arch. Luigi Figini and Arch. Gino Pollini (1960-63). The mapping process is therefore configured as a "cascade" process and has made it possible to create a synthesis database that contains the information related to each topic analyzed. The described mapping process is not only an element of knowledge of the territory but, at the same time, the starting point of a design process. The analytical choices, making some issues emerge from the maps more than others, identifying some areas on which to test the solutions, and working on specific elements of the "palimpsest" of the territory, have been chosen because they have determined the project guidelines on which the second part of the PURE research will be carried out.

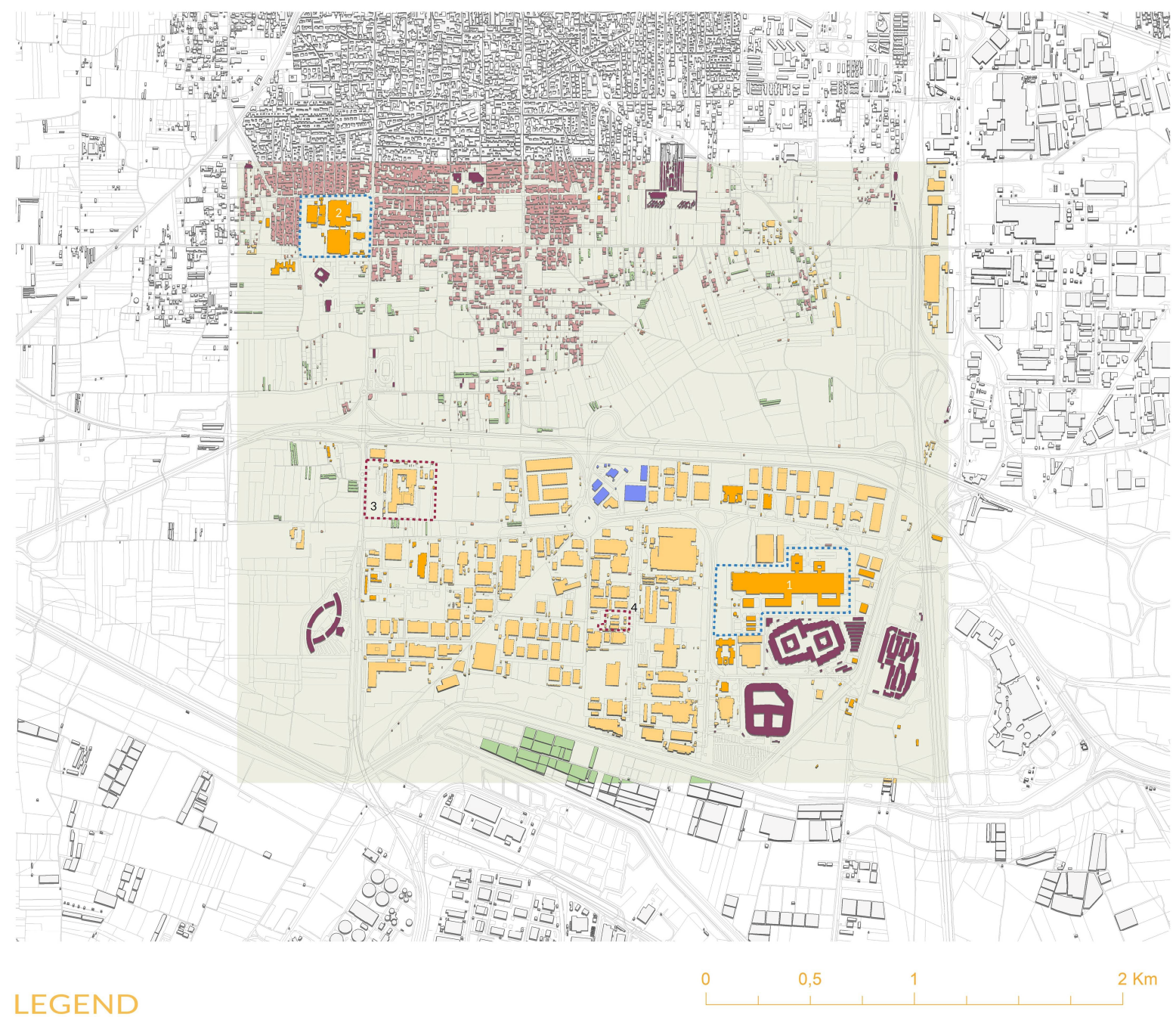

Active industrial facilities

Public facilities

[Schools, shopping centers, administrative and business buildings, sports buildings, cemetery]

Abandoned industrial facilities

Agricultural shacks

Greenhouses

Plants under construction

Residential buildings

Precious architectures and industrial artifacts

[1. Ex Olivetti; 2. Ex Marconi-Siemens]

Risky industrial facilities

[3. Eco-Bat Technologies; 4. Sol S.p.a]

Figure 8. Marcianise: focus scale. Settlements and building. Source: PURE team. 


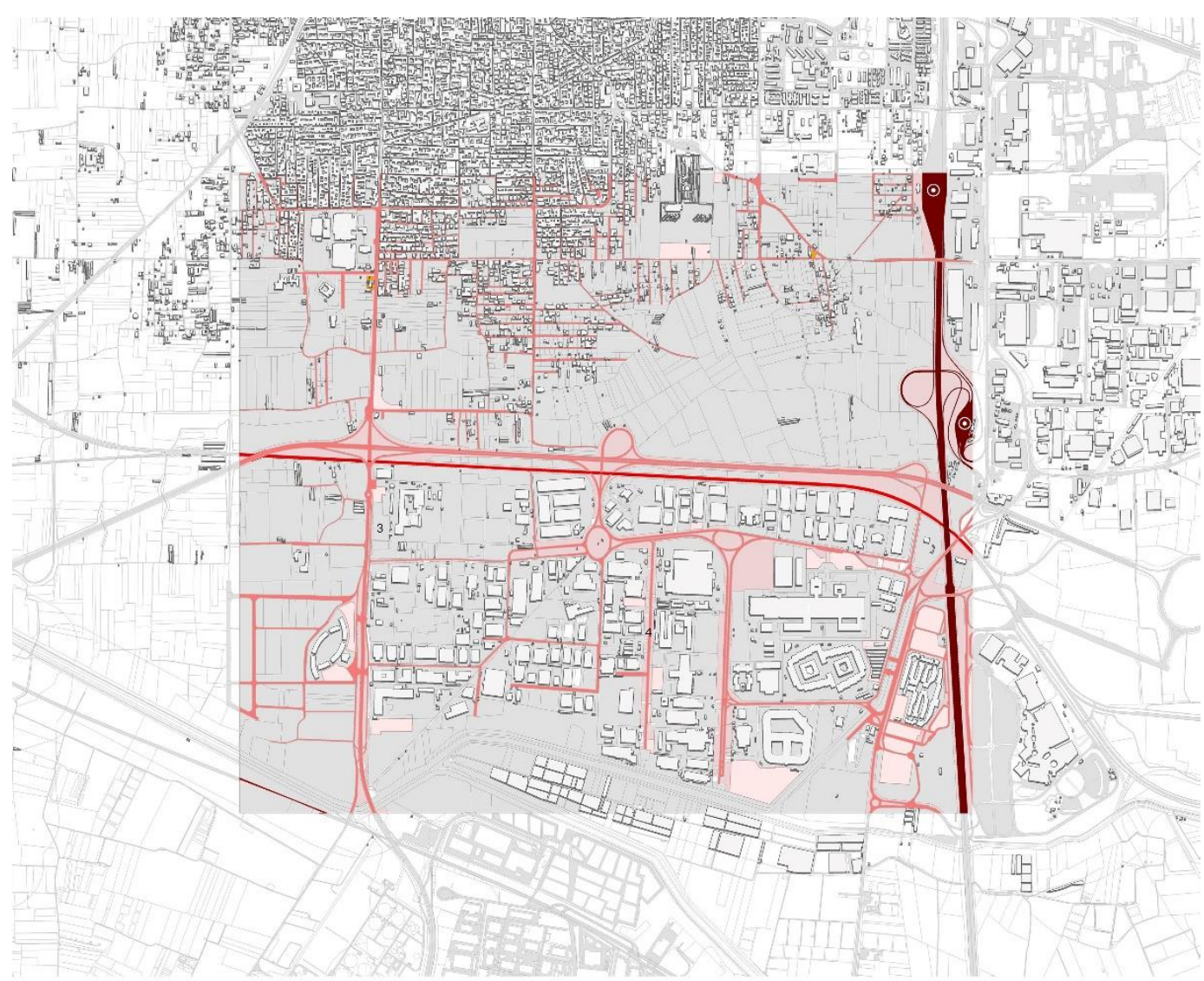

\section{Legend | Transport infrastructures}

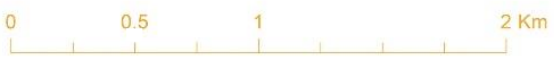

\footnotetext{
Fast transit roads

(-) Toll booth

High speed railways network

National railways

Other roads - Main and secondary roads

Trasportation buffer zones

Active petrol station

Parking site
}

Figure 9. Marcianise: focus scale. Transport infrastructure. Source: PURE team. 


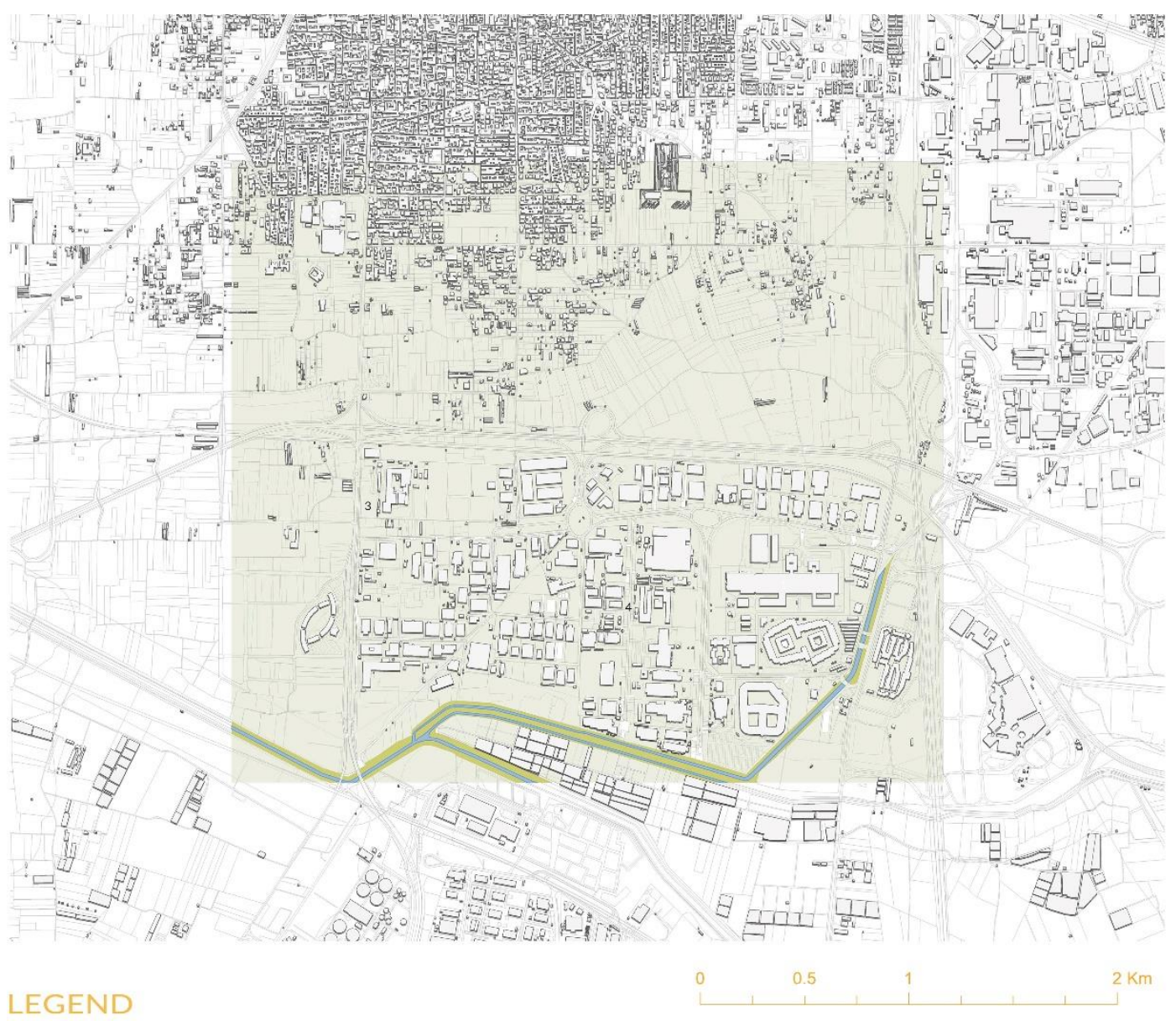

Water bodies

Figure 10. Marcianise: focus scale. Water system. Source: PURE team.

\section{Conclusions}

In giving an account and synthesizing an ongoing research process (PURE), the essay focuses on some specific territorial areas in relation to the planned establishment of large industrial areas. These are territories characterized by the coexistence of identities, functions and prospects of the future, which are different and often contradictory, in which the large industrial "plates" contend the territory with urban tissues, rural areas, large infrastructure and powerful signs of "historical palimpsest". For this "region" [24], located in Campania in the South of Italy and known at the time of the Romans as "Campania Felix", the essay coined the image of the "oil city", in which different entities contend the territory, without dialogue and in the absence of common strategies. For these territories, the question is not only the classic one of the regeneration of the abandoned industrial areas, but rather that of the governance of a complex process which, on the one hand, regenerates the permanently abandoned buildings, while on the other, reflects on the industrial question according to an innovative and ecologically equipped approach, making the large industrial slabs become integral parts and not in contradiction with the great urban conglomerate that has been generated since the second half of the 20th century from Naples to lower Lazio. The process of the analysis and knowledge of the places, first, and the definition of the strategies, elaborated by the PURE research, is part of this critical territorial condition trying to "disassemble" it by hypothesizing possible solutions. Of this complex path, this essay exposes, in a critical way, the part of the reading and knowledge of the territory necessary to develop the subsequent phases through masterplans on specific samples 
areas, which represents an area of urban transformation, a sort of "infiltration" of the city in the ASI platforms. In this sense, the results of PURE research can be implemented and replicated in similar contexts. The complexity is demonstrated, but also the need to correctly return this complex reality through a multiscalar and multidisciplinary mapping process, which represents both the fundamental background on which to draw up specific urban projects, and itself a form of metaproject and synthesis of reality in terms of the potential and criticality. The proposed methodological framework is a path of analysis and projects on a territory where up to now policies, programs and urban plans have always largely failed to fulfil their objectives.

Author Contributions: All the parts of this paper, including the reviewed versions of it, have been written and approved by all the authors: G.G., G.B. and V.V. Specifically, paragraphs 1, 2 and 3 are attributable to G.G.; paragraphs 4 and 5 to V.V.; and paragraph 6 to G.B. All authors have read and agreed to the published version of the manuscript.

Funding: PURE research project has been funded within the V:ALERE 2020 program (Rector's Decree. 475 of 9 July 2020).

Institutional Review Board Statement: Not applicable.

Informed Consent Statement: Not applicable.

Data Availability Statement: Not applicable.

Conflicts of Interest: The authors declare no conflict of interest.

\section{References}

1. Saraceno, P. Il Nuovo Meridionalismo; Istituto Italiano per gli Studi Filosofici: Napoli, Italy, 1986.

2. Viesti, G. Come Nascono i Distretti Industriali; Laterza: Roma-Bari, Italy, 2003.

3. Novacco, N. Politiche per lo Sviluppo. Alcuni Ricordi Sugli Anni'50 tra Cronaca e Storia; Il Mulino: Bologna, Italy, 1995.

4. Lepore, A. La Cassa per il Mezzogiorno: Alcune riflessioni su quarant'anni di intervento speciale. Patrim. Ind. 2011, 8, 48-56.

5. Broccoli, P. La modernizzazione di Terra di Lavoro (1957-1973); Rubbettino Editori: Catanzaro, Italy, 2019.

6. Guiducci, R. I livelli di autonomia nella programmazione. Mondo Operaio 1965, 4, 14-22.

7. Radogna, P. Sviluppo industriale e pianificazione territoriale nel Mezzogiorno. Urbanistica 1965, 45, 10-40.

8. Vittorini, M. Indirizzi strategici di assetto territoriale per l'inquadramento dei programmi di intervento nel Mezzogiorno. Urbanistica 1971, 57, 63-74.

9. Belli, A. Immagini e Concetti nel Piano. Inizi Dell'urbanistica in Italia; Etas Libri: Milano, Italy, 1996.

10. Salzano, E. Fondamenti di Urbanistica; Editori Laterza: Roma-Bari, Italy, 1998.

11. Dattomo, N. La legge 634/57 e il progetto di sviluppo per il Mezzogiorno. Storia Urbana 2011, 130, 8-10.

12. Parisi, R. Architettura e urbanistica per le aree di sviluppo industriale nel secondo Novecento meridionale. Patrim. Ind. 2011, 8, 57-69.

13. Adorno, S. Le Aree di Sviluppo Industriale Negli Spazi Regionali del Mezzogiorno. Available online: https://www.treccani.it/ enciclopedia/le-aree-di-sviluppo-industriale-negli-spazi-regionali-del-mezzogiorno_\%28L\%27Italia-e-le-sue-Regioni\%29/ (accessed on 12 February 2021).

14. Castanò, F. Il sicuro procedere dell'industria lungo la "via del sud". Il caso dell'Olivetti di Marcianise. Storia Urbana 2021, 165, $1-21$.

15. Formato, E. Reperti produttivi nel Mezzogiorno d'Italia: Lost in translation e potenzialità di trasformazione territoriale. Planum J. 2015, 194-201. Available online: https:/ / issuu.com/planumnet/docs/at1_pacchetto_complessivo (accessed on 12 May 2021).

16. Corboz, A. Il territorio come palinsesto. Casabella 1985, 516, 22-27.

17. European Commission. Eco-innovation the Key to Europe's Future Competitiveness. Available online: https://ec.europa.eu/ environment/pubs/pdf/factsheets/eco_innovation.pdf (accessed on 4 April 2021).

18. European Commission. Nature-Based Solutions Research Policy. Available online: https://ec.europa.eu/info/research-andinnovation/research-area/environment/nature-based-solutions/research-policy_en (accessed on 14 April 2021).

19. European Commission. Towards an EU Research and Innovation Policy Agenda for NatureBased Solutions \& Re-Naturing Cities. Available online: https:/ / ec.europa.eu/programmes/horizon2020/en/news/towards-euresearch-and-innovation-policyagenda-nature-based-solutions-re-naturingcities (accessed on 14 April 2021).

20. Berger, A. Drosscape. Wasting Land in Urban America; Princeton Architectural Press: New York, NY, USA, 2006.

21. Brenner, N. Implosions/Explosions: Towards a Study of Planetary Urbanization; Jovis: Berlin, Germany, 2014.

22. Allen, A. Environmental planning and management of the peri-urban interface: Perspectives on an emerging field. Environ. Urban. 2003, 15. [CrossRef]

23. Beauregard, A.R. When America Became Suburban; University of Minnesota Press: Minneapolis, MN, USA, 2006. 
24. Soja, E. Postmetropolis: Critical Studies of Cities and Regions; Basil Blackwell: Oxford, UK, 2000.

25. Merola, G. Metapiano per Caserta. Aree Industriali e Territorio Provinciale; Fiorentino: Napoli, Italy, 1995.

26. Shane, D. Recombinant Urbanism: Conceptual Modeling in Architecture. Urban Design and City Theory; John Wiley \& Sons Inc.: Chichester, UK, 2005.

27. Brenner, N. Stato, Spazio, Urbanizzazione; Guerini: Milano, Italy, 2016.

28. Galderisi, A.; Guida, G. Territori periurbani oltre la sostenibilità: Luoghi snodo per l'attivazione di strategie rigenerative. Arch. Studi Urbani Reg. 2020, 127, 76-99.

29. Garzilli, F.; Mazzarella, C.; Vittiglio, V. Integrated Approaches for PeriUrban Wastescapes: Eco-Innovative Strategies of the REPAiR Project in the Naples Case Study. Int. J. Urban Plan. Smart Cities 2020, 1, 43-58. [CrossRef]

30. Territorial Coordination Plan of Caserta. Available online: http://www.provincia.caserta.it/it/web/pianificazioneterritoriale/ home/;jsessionid=4C79C132058442DF94CA6FF84B6DE239 (accessed on 16 March 2021).

31. Fussler, C.; James, P. Driving Eco-Innovation: A Breakthrough Discipline for Innovation and Sustainability; Pitman Publishing: London, UK, 1996.

32. Kemp, R.; Foxon, T. Typology of eco-innovation MEI Project:Measuring Eco-Innovation. European Commission, Ago 2007. Available online: https: / /www.merit.unu.edu/MEI/deliverables/MEI\%20D2\%20Typology\%20of\%20eco-innovation.pdf (accessed on 10 April 2021).

33. IUCN World Conservation Congress. Nature-Based Solutions to Adress Global SOCIETAL Challanges_2016 036. Available online: https: / / doi.org/10.2305/IUCN.CH.2016.13.en (accessed on 14 April 2021).

34. Vittiglio, V. Recycling Wasted Landscape. Circular Perspectives and Innovative Approaches on Landscape Remediation. Ph.D. Thesis, University of Naples Federico II, Naples, Italy, 27 April 2020.

35. Palazzo, D.; Steiner, F. Urban Ecological Design. A Process for Regenerative Places; Island Press: Washington, DC, USA, 2011.

36. Cole, R.J. Transitioning from green to regenerative design. Build. Res. Inf. 2012, 40, 39-53. [CrossRef]

37. Girardet, H. Creating Regenerative Cities; Routledge: New York, NY, USA, 2015.

38. Newmann, P.; Beatley, T.; Boyer, H. Resilient Cities. Overcoming Fossil Fuel Dependence; Island Press/Center for Resource Economics: Washington, DC, USA, 2017.

39. Galderisi, A.; Guida, G. Un frame teoricometodologico per la rigenerazione dei territori periurbani. Un pilot case nel territorio casertano. Urban. Inf. Spec. Issues 2018, 278, 154-160.

40. REPAiR. D 5.3. Catalogue of Solutions Naples; Grant Agreement No 688920; EU Commission Participant Portal: Brussels, Belgium, 2019. Available online: http:/ / h2020repair.eu/wp-content/uploads/2019/10/Deliverable-5.3-Eco-Innovative-Solutions-Naples. pdf (accessed on 20 March 2021).

41. Russo, M. Multiscalarità. dimensioni e spazi della contemporaneità. Arch. Studi Urbani Reg. 2015, 113, 5-22.

42. Masetti, C. Dalla Mappa al GIS; Brigati: Genova, Italy, 2008.

43. Schroeder, P. Criteria for the Design of a GIS/2, Specialists' Meeting for NCGIA Initiative 19: GIS and Society. 1996. Available online: http:/ / www.spatial.maine.edu/ \{\}schroedr/ppgis/criteria.html (accessed on 23 April 2021).

44. Lakshmi Steinberg, S.; Steinberg, S.J. Gis Research Methods. Incorporating Spatial Perspectives; Esri Press: New York, NY, USA, 2015.

45. Bagnaia, R.; Viglietti, S.; Laureti, L.; Giacanelli, V.; Ceralli, D.; Bianco, P.; Loreto, A.; Luce, E.; Fusco, L. Carta Della Natura Della Regione Campania; Arpa Campania: Ispra, Italy, 2018. 